\title{
Compact Broadband High-Directivity Microstrip Directional Coupler
}

\author{
Bernardo M. Fabiani (D), Eduardo S. Sakomura (D), Tarcisio A. B. Gripp (D) \\ and Daniel C. Nascimento (iD \\ Laboratório de Antenas e Propagação - LAP, Instituto Tecnológico de Aeronáutica \\ 12228-900 São José dos Campos, SP, Brazil \\ bernardomoscardinifabiani@gmail.com,eduardosakomura@gmail.com,tarcisio.gripp@gmail.com \\ danielcn@ita.br
}

\begin{abstract}
The difference between phase velocities of the odd and even modes in inhomogeneous microstrip coupled lines makes the microstrip directional coupler a poor device regarding directivity. In this work, this issue is successfully compensated by the addition of a matching network at the ports of coupled lines. Furthermore, the proposed matching network, composed of a single segment of microstrip line, was extensively studied providing significant insights for the design of a compact and broadband device. As result, simple design equations based on coupled lines $S$-parameters are obtained, as well as the achievable operation limits of the proposed matching network. Finally, in order to validate the proposed design methodology, a compact microstrip directional coupler is constructed to operate with directivity higher than $30 \mathrm{~dB}$ and coupling of $17 \mathrm{~dB}$ over a $600-\mathrm{MHz}$ bandwidth.
\end{abstract}

Index Terms - Broadband, directional coupler, high-directivity, matching network, microstrip line.

\section{INTRODUCTION}

Directional couplers are important microwave devices employed in a diversity of high frequency systems for power splitting, combining, measuring, topology changing and filtering [1], [2]. Reflectometers and other power measuring devices generally require a high directivity (better than $30 \mathrm{~dB}$ ) for suitable performance [2]. However, directional couplers based on microstrip lines notoriously suffer from poor directivity [1]-[3]. This characteristic is a consequence of a well-known different phase velocities of the odd and even modes in inhomogeneous media. A number of solutions have been proposed in the literature to obviate this problem [4]-[9]. Nevertheless, most of the previous works do not provide simple equations or procedures that allow a systematic design, nor discussion about frequency performance, resulting in narrowband components [4]-[9], whilst broadband devices do not have a systematic design procedure [3].

In this paper, a novel formulation for the design of microstrip directional couplers based on output matching networks is presented. This design procedure provides a reduced-size, broadband and highdirectivity device. Basically, the work is organized as follows. In Section II, the proposed topology and its operation principle is described. Next, Section III describes a simple matching circuit that allows for easy design, alongside an analysis of the limits imposed by this component, whereas Section IV presents an analysis on how to enhance its broadband performance. Finally, Sections V and VI illustrate the Brazilian Microwave and Optoelectronics Society-SBMO received 8 Nov 2018; for review 22 Dec 2018; accepted 14 May 2019 
design, construction and characterization of a 2.2-GHz microstrip directional coupler with coupling of $17 \mathrm{~dB}$ for application in a phased array calibration circuit system [11].

\section{THEORETICAL MODEL}

The design methodology consists in the fact that matching simultaneously all ports of a reciprocal and lossless four-port network, a directional coupler with two pairs of isolated ports is obtained [1], [2]. Based on this, considering a bisymmetric four-port circuit represented by $[\mathrm{S}]_{\mathrm{CL}}$ in Fig. 1, all ports of the component are supposed to be matched by a two-port circuit represented by $[\mathrm{S}]_{\mathrm{M}}$. Manipulating the $[S]_{\mathrm{CL}}$ scattering matrix, the reflection coefficient $\Gamma$ that must be present at the coupled lines ports in order to satisfy the above-mentioned condition is given by (1). The parameters in this equation are exclusively due to coupled lines scattering matrix $[\mathrm{S}]_{\mathrm{CL}}$.

$$
\Gamma=\frac{-S_{21} S_{31}+S_{11} S_{41} \pm \sqrt{S_{21}^{2} S_{31}^{2}-S_{21}^{2} S_{41}^{2}-S_{31}^{2} S_{41}^{2}+S_{41}^{2}}}{-2 S_{11} S_{21} S_{31}+S_{11}^{2} S_{41}+S_{21}^{2} S_{41}+S_{31}^{2} S_{41}-S_{41}^{3}}
$$

Once calculated the reflection coefficient $\Gamma$ that must be produced by circuits represented $[\mathrm{S}]_{\mathrm{M}}$ and the fact that $\Gamma$, given reciprocity and losslessness, completely specifies $[S]_{\mathrm{M}}$, the next step consists in the matching network design. This circuit is synthesized in the next section using a single segment of a transmission line.

\section{MATCHING NETWORK}

A simple and efficient method to obtain $\Gamma$ is through a single segment of transmission line cascaded at coupled lines ports. The calculation of the characteristic impedance $\left(\mathrm{Z}_{\mathrm{Line}}\right)$ and electrical length $(\theta)$ of the matching line is given by (2) and (3), for a port termination $\mathrm{Z}_{0}$.

$$
\begin{gathered}
Z_{\text {Line }}=Z_{0} \sqrt{\frac{\operatorname{Re}(\Gamma)+|\Gamma|^{2}}{\operatorname{Re}(\Gamma)-|\Gamma|^{2}}} \\
\theta=\frac{\operatorname{Tan}^{-1}\left[\frac{2 \operatorname{Im}(\Gamma) \sqrt{\operatorname{Re}(\Gamma)-|\Gamma|^{2}} \sqrt{|\Gamma|^{2}+\operatorname{Re}(\Gamma)}}{\operatorname{Im}(\Gamma)^{2}+\operatorname{Im}(\Gamma)^{4}+\left(2 \operatorname{Im}(\Gamma)^{2}+\operatorname{Re}(\Gamma)^{2}-1\right) \operatorname{Re}(\Gamma)^{2}}\right]}{2}
\end{gathered}
$$

For a low loss transmission line, only a real characteristic impedance can be considered, and consequently a matching network is feasible if the $\Gamma$ satisfies (4) and (5).

$$
\begin{gathered}
|\operatorname{Re}(\Gamma)|<1 \\
|\operatorname{Im}(\Gamma)|<\sqrt{\operatorname{Re}(\Gamma) \mid-\operatorname{Re}(\Gamma)^{2}}
\end{gathered}
$$




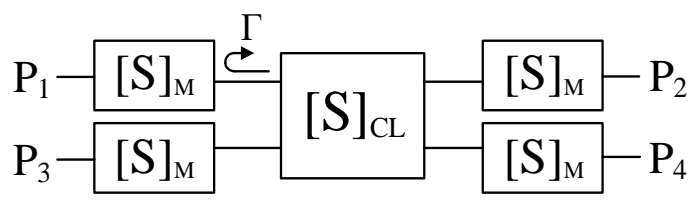

Fig. 1. Coupled lines connected to four matching circuits.

To illustrate the reflection coefficients achievable by this technique, a theoretical study presented on the $\Gamma$-complex plane (Fig. 2) was performed. In this figure, the unity circumference (black) gives the limit of all passive reflection coefficient, and the green circles provide all feasible $\Gamma$ using a single line segment. Considering the matching line designed with characteristic impedance $\left(Z_{\text {Line }}\right)$ comprised from $20 \Omega$ to $120 \Omega$, to avoid extremely wide or narrow microstrip lines, the achievable $\Gamma$ universe is described by the red and blue lines. The green-filled region is defined for $Z_{\text {Line }}$ out of the above considered limits. The red circumference locus shows the $\Gamma$ behavior when $Z_{\text {Line }}$ is constant, and its electrical length $\theta$ is tuned. Otherwise, the blue lines locus shows the $\Gamma$ behavior when $\theta$ is constant and $\mathrm{Z}_{\mathrm{Line}}$ is tuned. The understanding of this performance is a useful information in the design process. In addition, this analysis shows that a single segment of line is not capable of generating any one passive reflection coefficient.

\section{BROADBAND PERFORMANCE}

In this section, a broadband design with respect to the directivity and matching is presented. It is apparent that broadband performance can be achieved in the situation in which the S-parameters of both matching network and coupled lines suffer a slight variation in the operation range. As this behavior is observed in electrical small transmission lines, this paper proposes a procedure to find a small, easy-todesign matching network for a specified coupled lines length.

Starting from the set of equations modeling the microstrip coupled lines [12], the S-parameters for the calculation of $\Gamma$ is performed, which allows the generation of a curve for the matching network electrical length $\theta$ as a function of the coupled lines physical parameters.

By exploiting these functions, a graphic of $\theta$ [Fig. 3(a)] is plotted for coupled lines [Fig. 3(b)] of 8 $\mathrm{mm}$ length (less than a tenth of wavelength at $2.2 \mathrm{GHz}$ ) printed on a CuClad substrate with the dielectric constant $\varepsilon_{\mathrm{r}}=2.55$. The $\mathrm{u}$-axis is the normalized width line $\left(\mathrm{W}_{\mathrm{CL}} / \mathrm{t}\right)$, and the s-axis is the normalized gap $(\mathrm{g} / \mathrm{t})$, where $\mathrm{t}$ is the substrate thickness. Since the curve is generated, the user may select the dimensions of the coupled lines to ensure a small matching network, as described in the next section. 


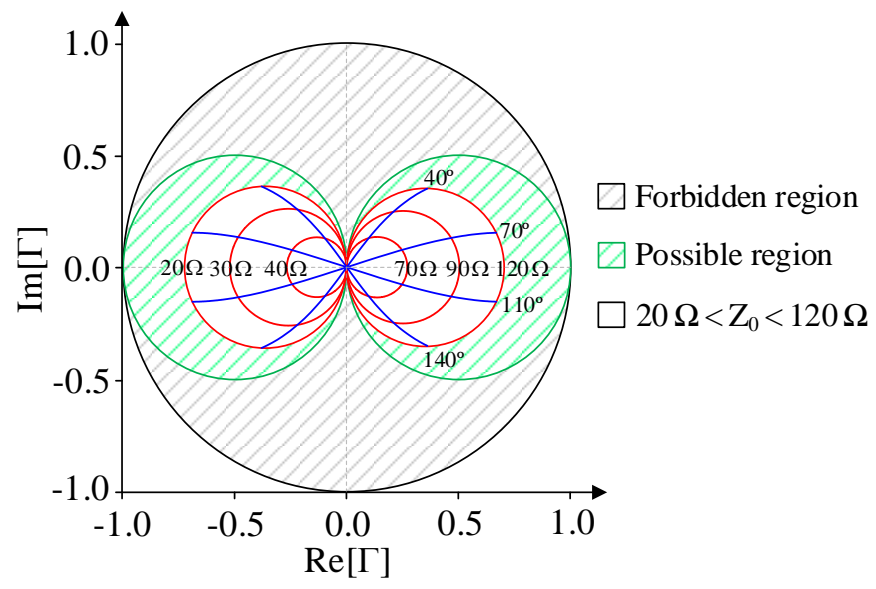

Fig 2. Achievable reflection coefficient on $\Gamma$-complex plane.

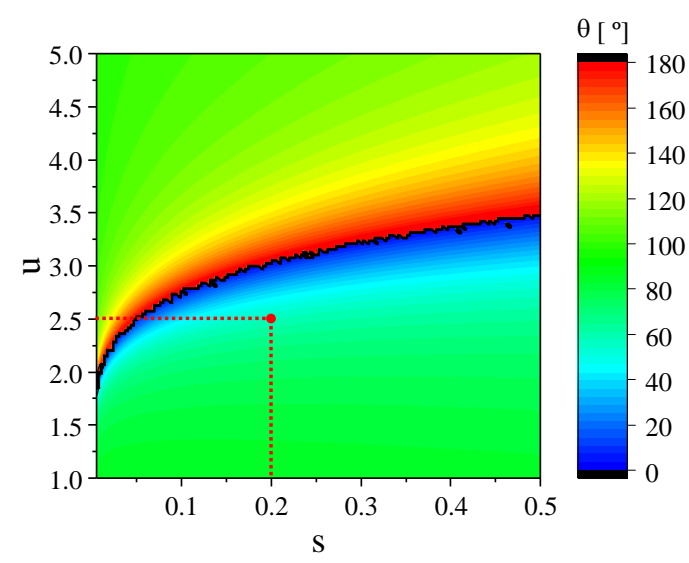

(a)

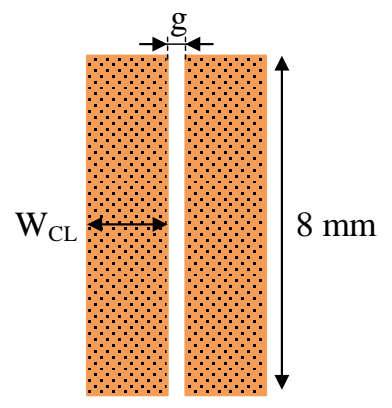

(b)

Fig 3. (a) Matching network electrical length as function of coupled lines parameters and (b) coupled lines geometry.

\section{DIRECTIONAL COUPLER DESIGN AND CHARACTERIZATION}

To demonstrate the proposed technique effectiveness, a 2.2-GHz directional coupler is designed as follow. The circuit topology is presented in Fig. 4, and is printed in aforementioned dielectric substrate with $\mathrm{t}=1.524 \mathrm{~mm}$ and $\tan \delta=0.002$.

Seeking for a coupling of $17 \mathrm{~dB}$ at $2.2 \mathrm{GHz}$, estimated using equations given in [12], the chosen dimensions from Fig. 3, restricted by the available milling tool, are $\mathrm{u}=2.5\left(\mathrm{~W}_{\mathrm{CL}}=3.8 \mathrm{~mm}\right)$ and $\mathrm{s}=0.2$ $(\mathrm{g}=0.3 \mathrm{~mm})$ that results in a matching network of 57 degrees. Furthermore, a not very small matching network facilitates the design of transitions between different lines.

The next step in the design consists of the analysis and optimization of chosen coupled line by using the accurate full-wave software HFSS [Fig. 5(a)], maintaining similar $\theta$ length and coupling. For the optimized dimension $\left(\mathrm{W}_{\mathrm{CL}}=3.4 \mathrm{~mm}\right)$, the magnitudes of the scattering parameters are presented in [Fig. 5(b)]. From this figure, as expected, the coupling is about $17 \mathrm{~dB}$ at $2.2 \mathrm{GHz}$ and the directivity is poor [1]-[3] (about $17 \mathrm{~dB})$. At operation frequency, the $S$-parameters are: $S_{11}=0.022 \angle 41.77^{\circ} ; S_{21}=0.986 \angle-37.24^{\circ}$; $\mathrm{S}_{31}=0.154 \angle 52.51^{\circ} ; \mathrm{S}_{41}=0.023 \angle-135.93^{\circ}$. Using these values in (1), the reflection coefficient for perfect isolation and matching is calculated as $\Gamma=0.075 \angle 28.65^{\circ}$.

Once the simulation of the coupled lines is completed, the next step consists of the design of the 
matching circuit using (2) and (3). It results in a matching line with length $\theta=61.26^{\circ}$ (at $2.2 \mathrm{GHz}$ ) and $Z_{\text {line }}=54.48 \Omega$.

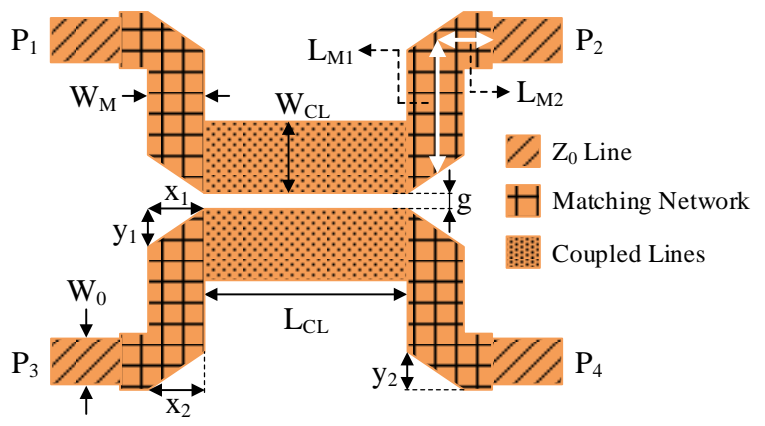

Fig 4. Proposed microstrip directional coupler.

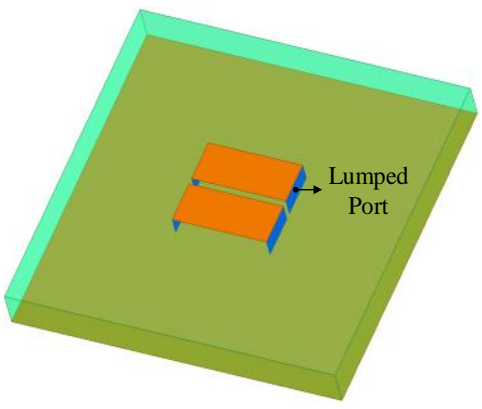

(a)

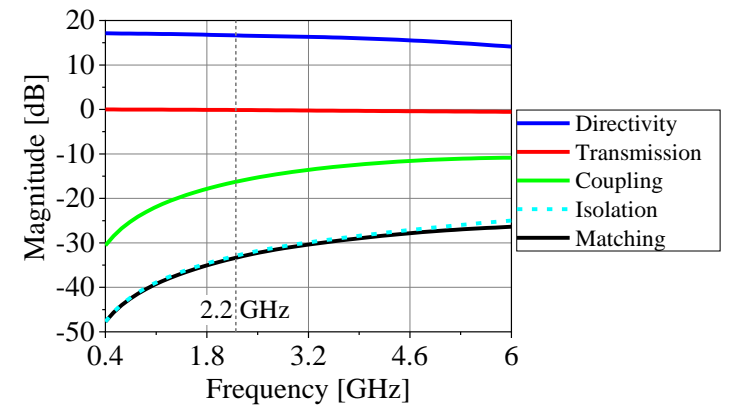

(b)

Fig 5. Coupled line: (a) in HFSS software and (b) parameters.

Finally, an optimization process was carried out in order to compensate the discontinuities effects [12] introduced by the chamfers and impedance steps, resulting in the final dimensions: $\mathrm{W}_{0}=4.22 \mathrm{~mm}$, $\mathrm{W}_{\mathrm{CL}}=3.43 \mathrm{~mm}, \mathrm{~L}_{\mathrm{CL}}=7.97 \mathrm{~mm}, \mathrm{~g}=0.3 \mathrm{~mm}, \mathrm{~W}_{\mathrm{M}}=4.67 \mathrm{~mm}, \mathrm{~L}_{\mathrm{M} 1}=6.39 \mathrm{~mm}, \mathrm{~L}_{\mathrm{M} 2}=3.48 \mathrm{~mm}$, $\mathrm{x}_{1}=\mathrm{y}_{1}=3.42 \mathrm{~mm}$ and $\mathrm{x}_{2}=\mathrm{y}_{2}=4 \mathrm{~mm}$. Results of simulated directional coupler, shown in [Fig. 6(a)], indicate at $2.2 \mathrm{GHz}$ a directivity better than $30 \mathrm{~dB}$, coupling of $17 \mathrm{~dB}$ and reflection coefficient at all ports better than $-30 \mathrm{~dB}$. It is important to point out that the coupling level does not change substantially across the design [Fig. 5(a)] and [Fig. 6(a)]. Also, as proposed, high-directivity and return loss, both better than $30 \mathrm{~dB}$, were achieved in a broadband $(0.4 \mathrm{GHz}$ to $4.6 \mathrm{GHz})$.

After the HFSS simulation, a prototype was manufactured and measured using the Agilent N5230A network analyzer, as presented in Figs. 6(a), 6(b) and 6(c). It is worth to mention that the termination loads used to measure the directional coupler S-parameters are the calibration loads of the network analyzer. The comparison amongst measured and simulated results is presented in Figs. 6(b) and 6(c).

These results, presented in Figs. 6(b) and 6(c), indicate that the prototype works as expected, presenting directivity better than $35 \mathrm{~dB}$ and reflection coefficient under $-30 \mathrm{~dB}$ within the $600 \mathrm{MHz}$ bandwidth, with $\pm 0.5 \mathrm{~dB}$ of coupling deviation centered at $2.2 \mathrm{GHz}$ [highlighted in green - Figs. 6(b) and 6(c)]. Given the high directivity and good matching features up to $4.6 \mathrm{GHz}$ present by this directional coupler, it can be used in others frequencies bands, as highlighted in blue - Figs. 6(b) and 6(c).

Understanding the slight differences between measured and initial simulated (red curve) results, an 
analysis of the directivity versus the impedance termination $\mathrm{Z}_{\mathrm{L}}$ deviation was carried out and presented in Fig. 7 for different frequencies. This analysis indicated that a deviation of the order of $1 \Omega$ would be enough to substantially change the directivity.

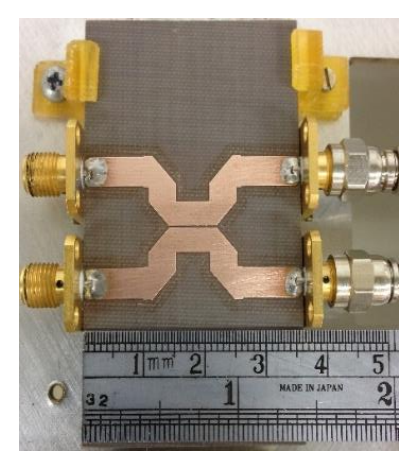

(a)

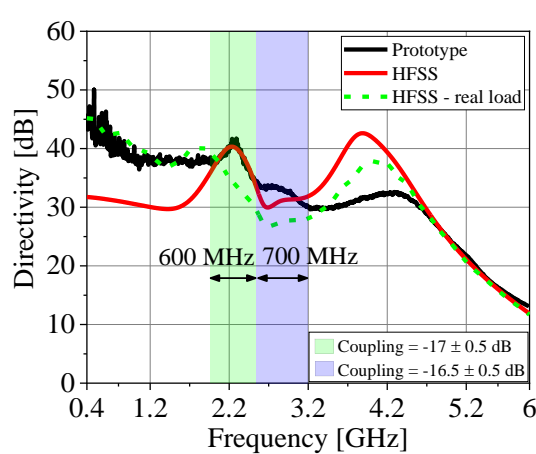

(b)

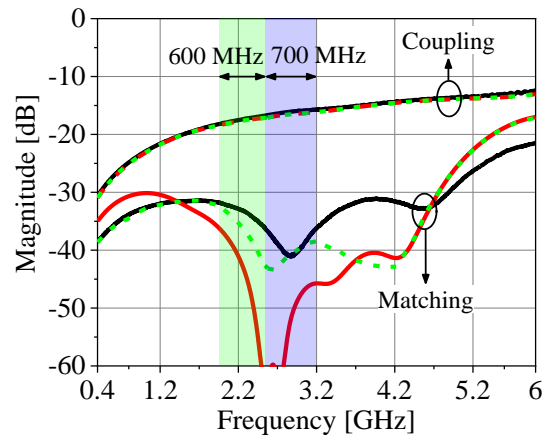

(c)

Fig 6. (a) Microstrip directional coupler prototype and directional coupler parameters: (b) directivity and (c) coupling and matching.

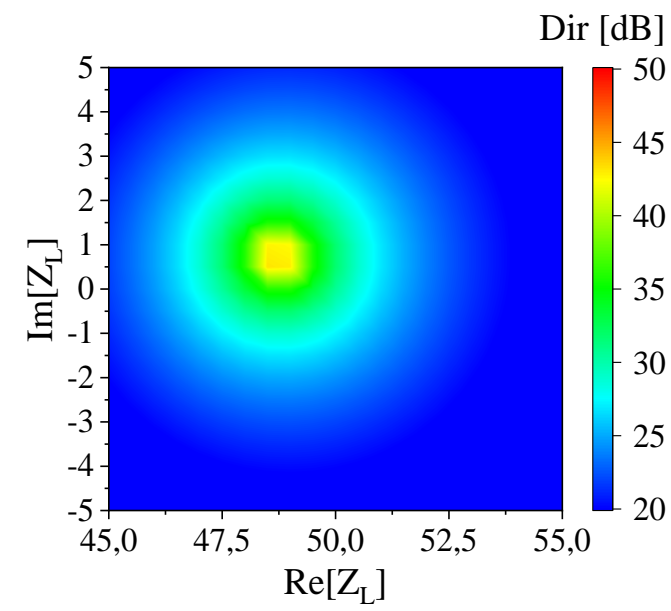

(a)

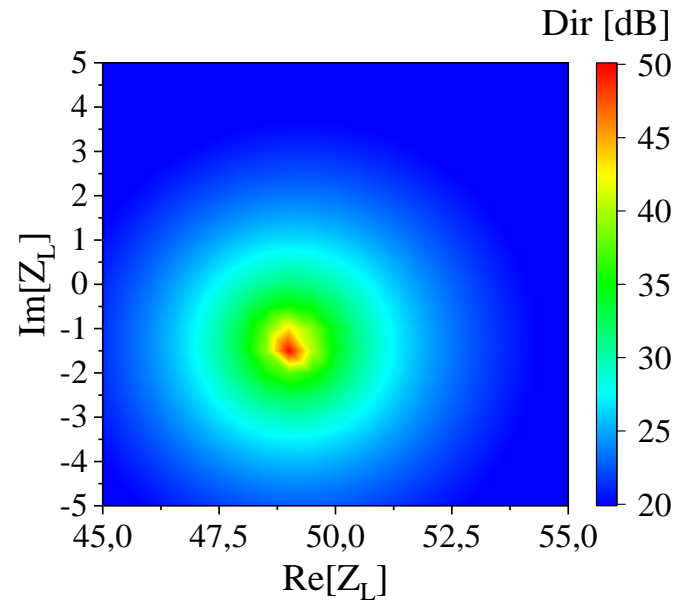

(c)

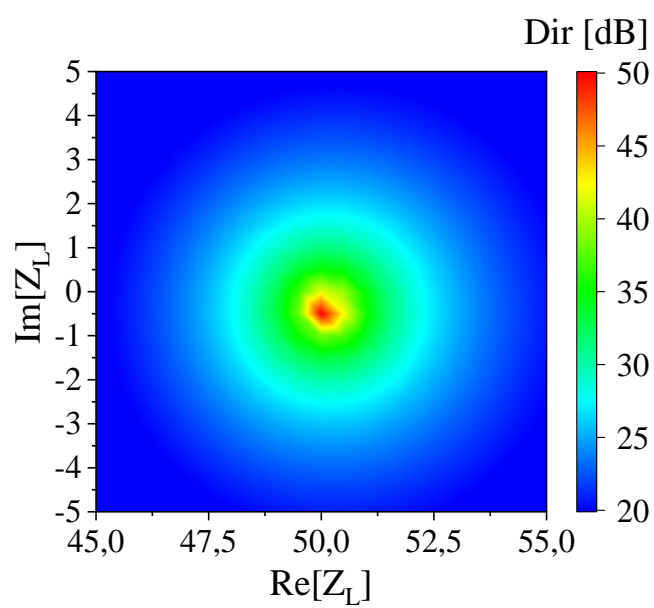

(b)

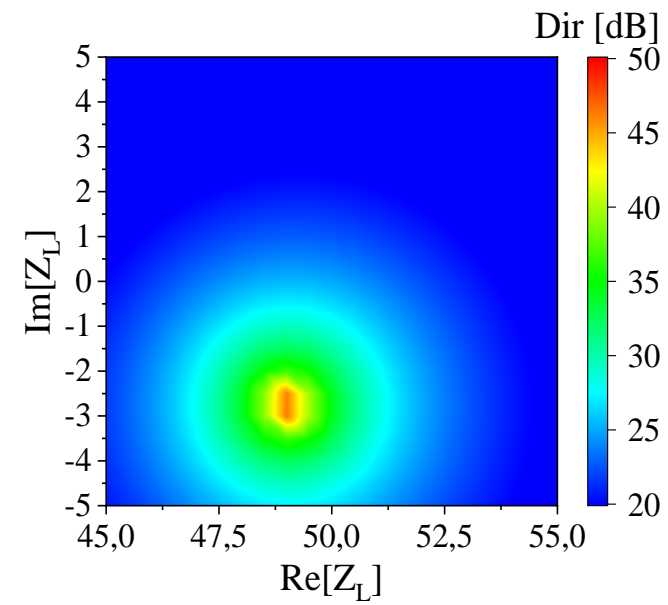

(d)

Fig 7. Directional coupler directivity versus $Z_{L}$ for some frequencies: (a) $1.2 \mathrm{GHz}$; (b) $2.2 \mathrm{GHz}$;(c) $3.6 \mathrm{GHz}$; (d) $4.8 \mathrm{GHz}$.

Therefore, for a better characterization, the termination load was measured in network analyzer and introduced in HFSS simulation, resulting in the HFSS-real load data, which agree better with the prototype curve. Since there are uncertainties in the measurement [13], [14] and in the manufacture 
process, simulation and experimental results are not totally in agreement.

\section{FINAL COMMENTS}

A new technique for the design of a high directivity microstrip directional coupler is presented in this paper. The proposed method allows the design and construction of a simple and efficient device which was ratified by a prototype manufactured to operate at $2.2 \mathrm{GHz}$. The proposed methodology allows for a high-directivity, matched, broadband and electrically small directional coupler and offers a systematic approach to its design.

\section{ACKNOWLEDGMENT}

The authors would like to thank CNPq for sponsoring Project 166603/2017-1.

\section{REFERENCES}

[1] R. Mongia, I. Bahl, P. Bhartia and S. Hong, RF and microwave coupled-line circuits. Norwood, MA: Artech House, 2007.

[2] D. Pozar, Microwave engineering. Hoboken, N.J.: Wiley, 2012.

[3] S. Uysal, Nonuniform line microstrip directional couplers and filters. Boston: Artech House, 1993.

[4] J. Park and Y. Lee, "Asymmetric coupled line directional coupler loaded with shunt inductors for directivity enhancement," Electronics Letters, vol. 46, no. 6, p. 425, 2010.

[5] Seungku Lee and Yongshik Lee, "An Inductor-Loaded Microstrip Directional Coupler for Directivity Enhancement," IEEE Microwave and Wireless Components Letters, vol. 19, no. 6, pp. 362-364, 2009.

[6] Sheng-Fuh Chang, Jia-Liang Chen, Yng-Huey Jeng and Chain-Tin Wu, "New high-directivity coupler design with coupled spurlines," IEEE Microwave and Wireless Components Letters, vol. 14, no. 2, pp. 65-67, 2004.

[7] T. Fujii, T. Kawai, I. Ohta and Y. Kokubo, "Design method of coupled-microstrip directional couplers based on equivalent admittance approach," Electronics and Communications in Japan (Part II: Electronics), vol. 88, no. 7, pp. 11-18, 2005.

[8] G. Valente, G. Montisci and S. Mariotti, "High-performance microstrip directional coupler for radio-astronomical receivers at cryogenic temperature," Electronics Letters, vol. 50, no. 6, pp. 449-451, 2014.

[9] L. Wang, G. Wang and J. Siden, "Design of High-Directivity Wideband Microstrip Directional Coupler With FragmentType Structure," IEEE Transactions on Microwave Theory and Techniques, vol. 63, no. 12, pp. 3962-3970, 2015.

[10] V. Tas and A. Atalar, "Using Phase Relations in Microstrip Directional Couplers to Achieve High Directivity," IEEE Transactions on Microwave Theory and Techniques, vol. 61, no. 12, pp. 4063-4071, 2013.

[11] B. M. Fabiani, "Circuito de alimentação para rede com apontamento de feixe," M.S. thesis, Dept. Elect. Eng., Technological Institute of Aeronautics, Brazil, 2017. In portuguese.

[12] E. Fooks and R. Zakarevičius, Microwave engineering using microstrip circuits. New York.: Prentice Hall, 1990.

[13] R. Witte, Spectrum and network measurements. Scitech Publishing Inc, 2014.

[14] J. Dunsmore, Handbook of microwave component measurements. Chichester: John Wiley \& Sons Inc., 2012. 